\title{
How we work: reflecting on ten years of inclusive Research
}

\author{
https://doi.org/10.1080/09687599.2021.1907546
}

Edurne García Iriartea , Gemma Díaz Garolerab , Nancy Salmonc , Brian Donohoed, Greg Singletone, Laura Murraye, Marie Dillone, Christina Burkef, Nancy Ledding, Michael Sullivanf and Marian Spelmanf

aFaculty of Arts Humanities and Social Sciences, School of Social Work and Social Policy, Trinity College Dublin, The University of Dublin, Dublin, Ireland;

bInstitute of Educational Research,

University of Girona, Girona, Spain;

cFaculty of Education and Health Sciences, School of Allied

Health and Health Research Institute, University of Limerick, Limerick, Ireland;

dNational Federation

of Voluntary Service Providers, Galway, Ireland;

eSwan Centre, Brothers of Charity Galway, Galway,

Ireland;

fClarin Services, Brothers of Charity Galway, Galway, Ireland;

gInclusive Research Network,

Limerick, Ireland

\section{ABSTRACT}

Inclusive research has gained momentum internationally. However important critiques of this approach query whether

inclusive research reinforces perceptions of deficit and contribute to exclusionary practices. This paper presents a reflection on the practices within an inclusive research group over the past decade, with a focus on decision making and support. The authors used thematic analysis to critically review minutes, workshop presentations and research reports. The findings indicate a shift in how the group works together; moving away from being guided by university supporters in the early years towards increased participation in decision making and ownership of the group's agenda by self-advocates over time although balanced collaboration across all members continues to be challenging. The article explains how the inclusive approach used by the group enabled self-advocates to not only conduct research, but to also critically review their own work.

Points of interest

- Research done together with people with learning disabilities, inclusive research, has become known worldwide. Some people wonder if teams that say they are inclusive are not really treating people as equal partners.

- Our group wanted to reply to these key issues as we think about how we work together.

- To do this, we looked at our meeting notes and agendas, reports, and training presentations over the past ten years. We looked at how we make decisions and the support we get.

The group found that self-advocates and supporters now work as full partners. University supporters made decisions before. Now self-advocates decide the research topics, methods, and the report. 
- In this article we explain how we work together and also what we think about the work we do. Even though we are happy with the way we work, we still struggle with how much work we all do.

\section{Introduction}

Inclusive research is defined by Walmsley and Johnson in their 2003 seminal text as a process of working alongside people with learning disabilities as research collaborators in the design, data collection, analysis, and dissemination of research findings. In a review of their work, Walmsley, Strnadova, and Johnson (2018) emphasise as key features of inclusive research: the contribution of people with intellectual disabilities to the research, which in turn contributes to social change, research that can be used for advocacy, and the commitment of researchers to the issues being researched and to those affected by them. Nind (2016) provides important quality criteria of inclusive research, including that the research responds to important questions and reaches participants in ways that could not otherwise be responded/accessed and that the research builds on knowledge by people with learning disabilities, it is recognised by them as authentic and impacts on their lives.

A useful framework to understand the participation of people with learning disabilities in research is provided by Bigby, Frawley, and Ramcharan (2014), who identify various contributions by people with learning disabilities to research: (1) members by experience of advisory panels where they participate as reviewers of research (e.g., for funding purposes or to establish research priorities), and as advisors of a project's direction or specific methodological aspects. In this type of contribution, people with learning disabilities have little control over their own participation in research; (2) research leaders who develop innovative research approaches, where people with learning disabilities control and conduct their own research about issues that are important to them and become "the objects of their own inquiry" (Bigby et al., p. 6); and (3) members of collaborative groups, where people with and without learning disabilities work together to create new, accessible ways to ask and 
answer pressing questions, with shared but also distinct interests, all equally valued. In this approach, control is shared by all members although the research process is generally led by a senior researcher. Covering a range of contributions, inclusive research has gained momentum and wider international initiatives align with the core elements of inclusive research such as Horizon Europe (European Commission 2019), which calls for increased citizen involvement in research production and citizen science, which aims at creating partnerships between researchers and the public to ensure research relevance and the democratisation of science (Hecker et al. 2018).

Although people with learning disabilities began to contribute to disability research later than other disability groups, such as people with physical disabilities (Goodley 2004), over the past two decades there has been an increased presence of inclusive research in academic literature published in English. For example, in 2004 the British Journal of Learning Disabilities (BJLD) published a special issue dedicated to disability research, with contributions co-authored by people with learning disabilities and reporting on inclusive (people-led) research. In 2012, people with learning disabilities guest-edited and co-authored another special issue in the same journal (Blunt et al. 2012). These contributions, however, were not without challenges. As an example, the guest editors of the BJLD (2012) special issue highlighted the diversity of opinions about complex language within the editorial process, with some advocating for only easy-to-read language while others argued in favour of clear writing with technical terms explained to promote deeper discussions. Another wellrespected source, the Journal of Applied Research in Intellectual Disability, published a special issue about inclusive research in 2014. The editors posed fundamental questions about the epistemological approach of inclusive research and queried whether inclusive research was a research paradigm or a method, and more fundamentally, about the added value of inclusive research (Strnadova and Cumming 2014), an issue addressed by Walmsley, 
Strnadova and Johnson (2018), who suggest that the most important added value of inclusive research is findings ways to work together and sharing them widely. Publication of inclusive research studies completed by and with people with learning disabilities has resulted in an emerging "first base" of peer reviewed literature on how inclusive research can be done (Nind, 2016, p. 193) (see e.g. Bane et al. 2012; García Iriarte, O’Brien, and Chadwick 2014; Kramer et al. 2011; Pallisera Díaz et al. 2015; Salmon et al. 2019; Tuffrey-Wijne and Butler 2010). As such, thoughtful critiques of this type of inclusive research are now arising, establishing what Nind (2016) identifies as a second wave of inclusive research publications, two of which are discussed next in relation to authorship of peer-reviewed publications and training in inclusive research.

In their systematic analysis of peer reviewed inclusive research, Strnadova and Walmsley (2018) identified different types of authorship of inclusive research publications: co-authored by academics and people with learning disabilities, of which some present an account of the writing process, and publications authored by academics alone, with some including quotations by people with learning disabilities while others focus on academics' own reflections of the research process. While acknowledging tensions between academic pressure for publication in peer-reviewed journals and selfadvocacy interests, which may have more suitable platforms for dissemination, Strnadova and Walmsley (2018) argue in favour of the transparency of the writing process, otherwise they note, such work can be viewed as tokenistic.

The ways that inclusive research teams provide support to people with learning disabilities is another point of critical reflection. Nind et al. (2016) analysed approaches to training in inclusive research processes and identified different types of training, drawing from training and capacity building models. In a number of approaches identified by Nind et al. (2016), people with learning disabilities have some control over their training needs and learn 
through experience conducting research: (1) apprenticeship, where persons with learning disabilities work with expert researchers; (2) lifelong learning, in which persons with learning disabilities have their own training needs and they have control over their training; and (3) challenging inequality, a training approach where all learn together and are supported to conduct good quality research. In contrast, academic researchers have control over the research process and address "research deficits" in other approaches: (4) addressing deficits, where persons with learning disabilities engage in research training with a focus on their lack of skills; and (5) formal, a training approach that includes a curriculum. Nind et al. (2016) critique deficit-based and formal training in favour of approaches that facilitate learning along the research process and are open to discussion about learning, questioning the idea that people with learning disabilities require upskilling to participate in research. The latter approaches include: (6) inclusive immersion, a training approach where learning occurs by immersion in the research context; and (7) dialogical approach, where inclusive researchers are able to learn together and examine each other's perspectives.

Despite the valid advances in critiquing inclusive research work, people with learning disabilities have been rarely included as co-authors of the peer-reviewed articles, and to the best of our knowledge, they have not been published in plain English or other accessible formats. While this issue has been acknowledged in the literature as legitimate "nonaccessible space" (Bigby et al., 2014), it potentially leaves people with learning disabilities outside critical discussions on inclusive research. Members of an inclusive research group authoring the current paper participated in a seminar series organised by Nind and colleagues in 2013 that informed their discussion on training presented above. Our earlier work (García Iriarte, O’Brien, and Chadwick 2014) was used as an example of formal and deficit-based approaches to involve people with learning disabilities in research training. This interpretation prompted an in-depth review of our own inclusive research work and forms the 
basis of this paper, which aims to answer the following question: How are people with learning disabilities (self-advocates) involved with university and other supporters throughout the research process? Specifically, the objectives of this project, entitled How We Work were:

(1) to critically reflect on decision-making processes; (2) to examine the support offered within the group to engage in research. To undertake this project, a specific process of generating and analysing data was conducted collaboratively by members of the group, which is presented below.

\section{Research process}

\section{Background}

\section{The Inclusive Research Network (IRN)}

The Inclusive Research Network (also referred to as the 'network') is a group of selfadvocates who self-identify as having learning disabilities (referred to as 'self-advocates'), support staff (referred to in this paper as 'supporters' to differentiate them from university supporters) and university supporters, who co-design and complete research projects to address issues of importance to people with learning disabilities in Ireland. The terms used in this paper were discussed and decided upon by self-advocates. Thus, self-advocates and, when needed, 'with learning disabilities' was chosen. In previous reports, we used 'coresearchers' but that word was not 'natural' to self-advocates involved in this project. 'University' was preferred over 'academic' as the latter was difficult to pronounce, and the term 'supporter' was chosen over 'researcher'.

The IRN was originally funded in 2008 with a European Union Marie Curie Actions grant with the aim to support self-advocates to conduct research and use findings to influence national policy regarding learning disabilities (Tierney, Curtis \& O’Brien, 2009). Three research workshops were organised between 2008 and 2009 by the National Institute for 
Intellectual Disability, located at Trinity College Dublin, a leading Irish university, in collaboration with the National Federation of Voluntary Service Providers, a national umbrella organisation for learning disability services with the purpose of developing selfadvocates' research skills (Tierney et al., 2009).

The IRN conducted four research projects between 2009 and 2019 and played an active role in advocacy, such as making policy submissions to government. Project one (Where We Live, 2009) used survey research to understand where people with learning disabilities lived and how they liked it. The second project (Relationships and Supports Study, 2010) explored relationships and the support of people with learning disabilities through focus groups while project three (Our Homes, 2015) examined people with learning disabilities' experience of moving houses using structured interviews. The most recent work, project four (Doctors and Us, 2019) explored access to health services by people with learning disabilities through focus groups.

When external funding to support the IRN was terminated in 2011, the network developed a two-year plan reflecting its commitment to research and advocacy and formed a self-advocate only steering group to lead the organisation and its activities. This structural change in leadership shifted power away from university supporters and professionals. The steering group consisted of self-advocates who originally held four elected positions — chair, vice chair, public relations officer, and treasurer - and one non-elected position, secretary. An average of 15 self-advocates and seven supporters, two of whom were university supporters, attended meetings since 2011. The larger network included other self-advocates who did not regularly attend meetings but who participated in data collection and analysis for specific research studies. A total of 87 self-advocates authored the four reports analysed in this paper. One self-advocate, the secretary, authored four reports, five self-advocates authored three reports, 17 two reports and the rest of self-advocates one report. Of those authoring more than 
one report, 13 typically continued to meet monthly at the time of writing this article. Some members had been involved with the network for a number of years, including those who held elected positions, while others had recently joined, resulting in experienced leaders working alongside new and less experienced members.

Self-advocates were men and women ranging in age from 20 to 65, from across Ireland. Some of the members who typically attended meetings withdrew from the network for various reasons such as not having enough support to attend meetings, health reasons, moving away to another county, retirement or death. Meetings were open to new members, some of whom were invited by support staff or self-advocates while others did not have previous contact with the network. All of the requests to join the network were accepted on the basis that self-advocates communicated their support needs for attending meetings, thus creating a flexible structure to learn about and to join the group. Network members travelled independently or accessed transport via support staff to participate in team meetings. The national umbrella service provider organisation provided office space and one day per week's salary for the secretary and administrative support to manage coordination and communication. University supporters from two partner universities (Trinity College Dublin and University of Limerick) provided methodological advice and practical assistance to 1) co-organise and host meetings; 2) respond to research queries; 3) support ethics applications; 4) co-design accessible information and research materials; 5) co-design data collection and analysis tools; 6) support data collection and analysis; and 6) collaborate on sharing research findings (García Iriarte, O’Brien \& Chadwick, 2014). This infrastructure remained constant over the years analysed in this paper although the dynamics of the partnerships evolved, as evidenced next.

Before describing how the current project, How We Work, was completed, details regarding practicalities of the network provide necessary context. From the outset, the team met 
approximately six times each year; however, in 2015 the team decided to convene monthly meetings to facilitate research projects, share personal and policy updates whilst more effectively planning transport. In the early years, the agenda was agreed by the steering group at the outset of the meeting; however, since 2015 the steering group met one week before monthly meetings to prepare the agenda and agree who would lead on each agenda item. University supporters and support staff of the steering group members were also present at the preparatory meetings. As the network members simultaneously worked on multiple projects (for example, a research project and a policy submission) and different parts of the same project (for example, data analysis and a conference abstract), task-specific working groups were formed with the voluntary participation of members, which often required work between the monthly meetings, for example with time-sensitive activities such as the submission of a conference abstract. University supporters were responsible for preparing accessible materials as agreed with the steering group. All network members decided the extent to which they participated in any of these activities, although limited support staff for some self-advocates was a barrier to taking part (García Iriarte et al., 2014). Self-advocates, supporters and university supporters typically collected and analysed data between monthly meetings. On occasion, monthly meetings were set up as workshops to collect data (for example, to conduct a focus group) or to analyse data (for example, to find meaning to quotes from interviews) for the convenience of network members.

\section{The How We Work project}

The first author presented the project idea at a monthly meeting in 2016, with previous approval from the steering group. The network agreed it was timely to reflect on how we worked together over the years. However, existing commitments and group workload meant that it was not feasible for the whole network to fully invest in the additional (and unfunded) 
How We Work project and paper. Thus, a smaller working group engaged on this project while the rest of the members progressed research that was already underway.

\section{Method}

The How We Work project was based on an analysis of existing documentation produced from 2009 to 2019 while the network undertook four research projects. The large volume of textual sources linked to the network provided rich historical data for critical analysis. Once ethics approval was granted from Trinity College Dublin in October 2017, the first author, a university supporter since 2009, and the second author, who was on study exchange and attended four group meetings in 2017, compiled materials for analysis. This study is primarily based on the meeting minutes, which the secretary recorded. In total, 37 sets of meeting minutes were available, 12 corresponding to the period 2009 to 2014 , and 25 to the period 2015 to 2017 . Additional materials were incorporated into an analysis of the meeting minutes to provide further background including research handbooks with guidance on recruitment of participants and data collection (5); project reports (4); one video script and two video files developed for research purposes; power point presentations to guide meetings and workshops (10); accessible research support documents, data collection pilots and notes with feedback from meetings and workshops (22); letters to politicians (2); and internal team emails (2) (all used with explicit permission). In total, 85 documents were selected and included for analysis in the How We Work project.

\section{Data analysis}

The analysis was conducted systematically by examining each record and by selecting all extracts concerning decision making and support. Data was anonymised, inputted into an excel sheet, and analysed thematically (Patton, 2015) in two phases. In the first phase, all the raw data was read and organised by the second author, with clarification and contextualisation provided by the first author. This enabled identification of key decision 
making and support processes within the team. The second phase of analysis involved university supporters, self-advocates, and their supporters discussing key points from phase one to develop a nuanced and shared understanding within the research team at three meetings in 2018 .

A university supporter facilitated the review and reflection on the preliminary analysis at the first meeting. Selected illustrative quotes on decision making and support to conduct research from the four projects undertaken by the network were presented to self-advocates and their supporters and a number of questions were posed to explore how the network made decisions (e.g. Who makes decisions?, What role do self-advocates have in making decisions?, What role do university supporters have?) and how the network was supported to conduct research (e.g., How do people get involved in research projects?, What is good about the way we learn?, What could be better about the way we learn?, What training type does the network fit in?). Following the discussion of quotes, self-advocates and supporters reviewed Nind et al.'s (2015) training classification and considered Bigby et al.'s (2014) collaboration types. Selfadvocates identified which training models and collaboration types they felt best represented the network's approach to research in relation to the four projects analysed. The main points from the discussion were recorded by the university supporter, then emailed to self-advocates and supporters who attended the meeting to check for accuracy. Two additional meetings involved smaller working groups of self-advocates and supporters with the aim to review the comments generated in previous discussions and to further analyse the data.

\section{How did we write this article?}

The university supporters drafted the manuscript based on the joint analyses and discussions with self-advocates and their supporters, as detailed above, and then shared it with all authors. University supporters were responsible for incorporating everyone's feedback and for submitting the manuscript to this journal. The university supporters asked the self- 
advocates that wanted to author the paper how they wanted to contribute to the paper and how their ideas should be recorded at one of the monthly meetings. If a supporter worked alongside a self-advocate who decided to author the paper, the supporter was also invited to be a named author.

Advice from Strnadova and Walmsley (2017) on authorship of inclusive research was reviewed. It was agreed to explain at the start of the paper that what we stated in this paper was the result of collaborative work and to use quotes from self-advocates to differentiate their voices from the voices of university supporters. The summary of key points and the recommendations were drafted jointly by self-advocates and supporters with the facilitation of the first author. Self-advocates and supporters, with help from two of the university supporters, developed an easy-to-read version of this paper using plain English language and pictures (http://www.fedvol.ie/Inclusive_Research_Network_IRN/Default.241.html).

\section{Findings}

The findings are presented in two sections addressing the objectives of the study. The first section presents key themes that we identified in relation to the process of decision making. The second section elaborates how the network approached research support. The longitudinal nature of the analysis allows for a comparison across studies and examination of changes over time. In brief, the analysis presents an evolution from a university/professional supporter-led group to a collaborative approach in which everyone's expertise contributed to research development.

\section{'Self-advocates make decisions and university supporters guide'}

This section explores how decision-making processes evolved over time in relation to research topics, data collection methods, fieldwork, data analysis, and dissemination. Selfadvocates identified that, at the time of writing this paper, they made decisions about specific 
aspects of research projects while university supporters guided them (Minutes, February 2018).

Research topics

'Only self-advocates vote’ (Meeting, February 2018).

The development of decision-making processes around research topics reflects the change in the network's structure in 2012, from research training workshops led by university supporters initially, to monthly meetings with a steering group made of self-advocates.

Decisions about projects one and two were made at the initial training workshop in 2008 . The process of decision making for projects three and four involved brainstorming research ideas, full and small group discussions carried over a number of meetings, including discussion of relevant literature, information provided by university supporters, and a final vote by selfadvocates.

The initial training workshops, conducted in 2008 to train self-advocates in research skills (referred to above), followed a cognitive apprenticeship methodology (Collins et al, 1989) that consisted of experts demonstrating their skills and facilitating participants (self-advocates and their supporters) in the use of their newly acquired skills in real-life situations (Tierney et al., 2009). During the first workshop, self-advocates identified, through brainstorming and discussion, two topics that became the focus of the first two projects: community living and relationships.

The decision-making process for the third and fourth projects followed a different path. On the conclusion of the second project, university supporters asked self-advocates about the topics they would like to research next. Self-advocates filled a form with their ideas. Through this exercise, the network identified and discussed a total of ten topics for the third research project. 
Transport, money, housing, the effects of cutbacks, changes in disability policy, independence, support, choice, employment and work, relationships. (Minutes, February 2012)

A secret ballot was organised to decide on the next research topic. Each self-advocate picked the three most important topics from the list. The topics with the most votes were home and independence. The network then decided to follow up with: 1) a training workshop on getting started on a research project; 2) a meeting to discuss the literature on the topics of home and independence.

The training workshop was divided into two sessions. The first session involved a discussion by self-advocates about what housing and independence meant. The second session aimed to brainstorm research questions in relation to each of the topics. The training workshop, facilitated by a university supporter, allowed for the gathering of self-advocates' expertise on the topic and the grounding of the project on their lived experience.

These two questions resulted in a lot of information on both subjects [home and independence] (...) We then broke into five groups to find two questions. All groups brought back at least one question. This feedback was read out to the main group. (Minutes, September 2012)

The literature review meeting was held a month after the training workshop and involved presentations on the themes of housing and independence. Self-advocates and supporters worked in small groups to present the findings from the first research project by the network, on community living (Inclusive Research Network, 2009) along with findings from key external reports including empirical research and national policy on community living. Following the presentations, the steering group chair (a self-advocate) facilitated a discussion on the focus of the project: 
It was agreed that we will focus on individual stories of people creating change in their lives about where they live - many moving from institutions (Minutes, October 2012)

Similarly to the third project, for the fourth project a discussion of ideas over a number of meetings was followed by a secret ballot cast only by self-advocates. Although university supporters did not vote, they had great influence in the decision-making process as shown below. At one of the meetings in which research ideas were discussed for the fourth project, one of the university supporters shared information about funding available for research projects focused on health.

[Applications can be made for] funding [for] partner projects between university and service users [up to] $€ 200,000$ available for the next two years. Group to look at getting funding if our next project is on health. (Minutes, April 2016)

The idea of a health research project was discussed over a number of meetings. At one of these meetings, members of the network discussed reasons to do research on health, and on two other topics that had been previously identified, education and money, which were gathered in a flip chart to help members make a decision. A secret ballot on the project by self-advocates with ballot cards prepared by the secretary then took place:

[A steering group member] was the returning officer and gave the result: education five votes, money five votes, health 12 votes. (Minutes, September 2016).

Over the next two meetings, self-advocates selected words related to health and came up with some questions. The network agreed on the main research question for the project in December 2016.

In short, the decision-making process on research topics evolved from an initial approach of discussion limited to one meeting to a deliberation process extended over time that helped everyone to unpack meaning, ground the topics in the lived experience of self-advocates, and 
to make a final decision through voting by self-advocates. While self-advocates were clear about their decision-making power, the data reveals that the influence of university supporters continued to be determinant in the final vote as the example about the health project illustrates.

\section{Fieldwork}

'Fieldwork is about other people with disabilities so we should be doing it' (Minutes, February 2018)

Self-advocates and their supporters took a very active role during fieldwork. University supporters engaged very little with data collection, unless self-advocates did not have any support staff to work directly with them, in which case, university supporters also provided guidance and logistical support to self-advocates on recruitment and data collection. It was the choice of self-advocates to engage as researchers, participants or both in the different projects and to decline participation in fieldwork. For example, in the third and fourth projects, self-advocates insisted on telling their stories first (as participants) before collecting data from others (as researchers), as illustrated in the following quote:

Eight self-advocates said that they want to take part in a focus group. Four selfadvocates said that they want to co-lead a focus group (Minutes, November 2017) While evidence on the active role of self-advocates and supporters during fieldwork is abundant, the analyses could not track the decision about this approach in the minutes or reports. Therefore, the university supporters brought this tacit arrangement up for discussion at the first analysis meeting of the How We Work project. Self-advocates identified the following reasons to actively participate in fieldwork. Firstly, they thought they were in a better position to understand issues than university supporters were and they felt ownership over the process: 'We understand it more', 'It's about other people with disabilities so we should be doing it', 'We can relate better to people with learning disabilities', 'They feel 
more comfortable in our company'. Secondly, self-advocates felt collecting data was a way of motivating other people with learning disabilities, demonstrating they could do research and building their confidence and research skills: 'Motivate people to get involved when it is their own project, with support', 'We want to be the main part of the research to show that we can do it', 'Build confidence in [speaking] up and skills', 'So we can learn more [about] research and get more ideas for future topics'. Finally, a logistical reason was provided that supported their active involvement in field work 'We know people in services in an area that we would do the focus group' (Minutes, February 2018).

\section{Data collection}

'University supporters share different types of methods to do research (...). We choose and work together' (Meeting notes, February 2018).

Decision-making mechanisms for research methods developed over the four projects undertaken by the network. The first project, on community living, involved a survey questionnaire with the aim of transferring skills learned at the initial research workshops. Self-advocates developed and tested the questions. University supporters advised them with the questions' wording, their order and selecting pictures (Inclusive Research Network, 2009). For the second project, on relationships, the network made a decision about data collection methods through voting:

The university supporters sent the self-advocates (...) and supporters information about: surveys, focus groups, interviews and the work we had to do with each method. The self-advocates (...) and supporters made the decision to do focus groups. (Inclusive Research Network, 2010)

Decisions about data collection methods for the third project, on home and independence, were made through several consultations and meetings over an extended period of time. Initially, the network expressed an interest in the stories of people who had moved to the 
community and led independent lives 'It was agreed that we will focus on individual stories of people creating change in their lives about where they live' (Minutes, October 2012). As the group started suggesting questions to gather these stories and providing feedback on the questions, the method developed into a structured interview including seven sections and over 40 questions.

'And we made a decision on the data collection method: structured interview.' (IRN, 2010).

The fourth study also involved a process of information sharing about methods of data collection, interpreting the information through role play and a group vote.

Members [of the network] did role play to explain the different ways of doing research. (...) a survey; (...) an interview; (...). We talked about (..) good and bad things of each method. [The secretary] had prepared ballot cards (...). The results were (...): interviews ( 1 vote); photos (7 votes); survey ( 0 vote); focus groups (12 votes, this is the winner). One member gave a very good idea to use photos and pictures as well as the focus groups. That way people could bring photos to explain something, e.g., a step to a doctor's surgery which makes it hard for a wheelchair user. The method of focus group with photos was agreed. (Minutes, November 2016) Data analysis

'We learn from other people's story' (Minutes, February 2018) A similar approach to decision making about data analysis methods was followed in the first three studies. The network evolved from a university supporter-led approach to data analysis to a progressively more collaborative approach. Procedures for data analysis involving discussion, role play, and accessible data presentation are summarised below. University supporters proposed conducting preliminary analyses to manage and make accessible the large amounts of data generated in each study. Project one used easy-to-read bar charts with 
pictures to present quantitative data that was explained and discussed with self-advocates (Kramer et al., 2011).

The facilitators [university supporters] entered the data into a computer file and did statistical analyses. The facilitators (...) used a series of bar charts with pictures. Seven self-advocates and two supporters (...) discussed the findings; compared the findings from the study with self-advocates' experiences of doing the survey. (IRN, 2010)

For project two, university supporters shared a preliminary analysis of themes with selfadvocates and their supporters. A meeting followed, in which university supporters and selfadvocates discussed the summary and the credibility of themes. The discussion was preceded by self-advocates role playing the themes.

We met to discuss what people said in the focus groups and the summary of themes. (...) University supporters asked these questions: Is this a good summary?; Is this what people said?; (...) We used coloured cards to say: it's a good code; I don't like the code; I have a better code. (IRN, 2010)

Project three also involved preliminary analyses of qualitative and quantitative data by university supporters followed by a presentation of the results for discussion with selfadvocates and their supporters. In contrast to project two, in which self-advocates validated the themes previously identified by university researchers, in project three, self-advocates worked with university researchers from an earlier stage in the identification of themes. Firstly, self-advocates were interested in reading the stories and in conducting the analysis '[The network] agreed they would like to read the stories of everyone who responded' (Minutes, July 2014).

Thematic analysis was conducted by extracting common themes from the stories. The university supporters' role consisted of assembling the stories, taking notes from the 
discussion, and presenting the quotes to self-advocates, who identified the best quotes illustrating each theme and brainstormed ideas for pictures to provide visual cues in the final report.

We broke into groups to look at findings (...) and found common themes from (...) the stories (Minutes, February 2015)

The working groups (...) then had to read or listen to the main point, circle the quotes they thought best showed that point, and then made a list of ideas for pictures to connect to each quote. (Minutes, March 2015)

\section{Dissemination}

'It is a privilege to have our names listed in the book as self-advocates' (Minutes, February 2018)

Dissemination of research findings in inclusive research has responded to academic pressure for publication as well as self-advocacy needs (Strnadova and Walmsley, 2017). Findings from the projects conducted by the network were shared through easy-to-read reports, presentations in advocacy, professional and academic conferences, articles in academic journals and professional magazines, service providers meetings, two report launches, video, and academic workshops at universities. In most cases, dissemination involved the collaboration of different members. For example, for project three, self-advocates decided to write an easy-to-read report about the project, organise a report launch, and record a video.

[One self-advocate] and [one university supporter] chaired a group on how to present the findings of the study (...): Magazine (21 (...) members), Video (17 (..) members), Book [easy-to-read report] (13 (...) members) (Minutes, February 2015) An opportunity to present the findings of project three was also provided through a supporter who was responsible for organising a service provider conference. 
[Supporter] told everyone about the [service provider] conference (...). He asked for someone from the [network] to present at the event. [Two self-advocates] agreed to present Our Homes study (Minutes, September 2016)

Similarly to the issue about self-advocates' involvement in fieldwork, there was no evidence available to track the decision about the dissemination of research findings through easy-toread reports. Self-advocates identified the following reasons underpinning this way of working: easy-to-read reports were a good way of documenting the studies 'It keeps track of what we have found out' and of presenting the information 'We as researchers want to show the work we have done to people we know and who are involved in our services'. 'A book [easy-to-read report] is a very good way of showing this information', 'Making it accessible so all can understand, people can learn from the pictures'. They also took pride in being authors of the book 'It is a privilege to have our names listed in the book as self-advocates' (Minutes, February 2018).

\section{'All learn together, all need support to conduct good research, very much IRN'}

(Minutes, February 2018)

Although research support was originally conceptualised as research training and technical logistical support to self-advocates prior to conducting field work, as the network evolved, more sophisticated and nuanced forms of research support became evident. Self-advocates who reflected on the way we learned as part of the How We Work project identified that our way of working responded to a collaborative approach in which members shared their expertise to develop methods together.

University supporters share different types of methods to do research and we choose the methods and work on them together by trial and error. (Minutes, February 2018). How the network approached training and other forms of material, social and emotional support are presented below. 
Training. The review of the minutes provided evidence that the network had approached training in different ways over the years. Firstly, the minutes refer to training days and training workshops on several occasions. As such, the network was initially set up through three training workshops which have been described earlier. Once the steering group was established, training days had two principal functions. First, training was arranged to involve the wider network membership in preparation for the study fieldwork (for example, review of consent forms, interview/focus group schedule) (see García Iriarte et al., 2014). For example, a training day was held to practice asking interview questions for the third project:

The university supporter presented the [fieldwork] handbook (...). Then, selfadvocates practiced with the interview questions (...). Notes were taken of changes to some of the questions which the university supporter agreed to do (...). (Minutes, March 2014)

Second, training workshops were organised with a small number of self-advocates around specific aspects of the research project such as developing research questions and completing ethics applications. For example, the network held a training day to complete the ethics application for the fourth study.

The university supporter presented the application form to the self-advocates and while going through it, the university supporter explained what everything meant, and we all together filled it in on the go. (...) We used the consent form of the previous study (...). But we decided that the university supporter and some self-advocates would meet again to add pictures of 'thumb up' and 'thumb down' instead of 'yes/no', and to add more symbols instead of words (Minutes, September 2017) Analysis of meeting minutes suggests that training became a broad term to refer to workshops to develop research skills, network meetings to provide guidance about fieldwork, and working meetings to address specific aspects of the research process such as ethics. 
Self-advocates also reflected on the training categories identified by Nind et al. (2015) and concluded that the network used aspects of all training types except 'formal training' and 'addressing deficits', which were immediately discarded as not representative of the network's approach to research. For example, self-advocates said that 'We work together and always control the decisions', 'We have control over the training but we need advice from university supporters, otherwise we are lost', 'We all learn together and all need support to conduct good research', 'We learn from other people's stories which they say and by taking part', and 'We learned a lot from our research [Our Homes], through the training, research, findings and report' (Minutes, February 2018).

As self-advocates and supporters gained experience of conducting research, their participation in and influence on the projects became more noticeable and counter-balanced that of university supporters. Their journey in inclusive research originated in participating in training workshops and they gained progressive involvement in all aspects of the research and running of the network, including training development and identification of training needs. As an example of the collaborative work around training, self-advocates, supporters and university supporters recorded a video on how to conduct fieldwork for the third project. Self-advocates and supporters revised a video script drafted by a university supporter and acted short scenes to show: what the study was about, information and consent forms, how to recruit participants, how to conduct the interview and how to send the information for transcription and analysis. As one self-advocate mentioned, 'We did a video, and that's training' (Minutes, June 2019). The video was distributed to all self-advocates involved in fieldwork. An example of self-advocates identifying training needs comes from a meeting in the context of the fourth project.

The group agreed on these ideas: 1 . There will need to be two leaders per focus group (one self-advocate and one supporter) 2. We need recorders 3. We need to set 
questions for the focus group - have a script and photos 4 . We need to agree on photos to use 5. Apply for ethics 6 . Talk about how to include people who don't use words to express their ideas. 7. Self-advocates need training in how to lead focus group. (Minutes, December 2016)

Research training was complemented with material, social and emotional support.

Material support. The network was supported by the research infrastructure available to two university supporters (one of them from 2012) and one service provider umbrella organisation, which facilitated access to meeting venues at their premises and the booking of such venues, hardware and software to develop materials, store and analyse the data collected, financial support to produce research materials such as printing handouts, fieldwork handbooks and easy-to-read reports, and to cover the expenses associated with research launch events. University supporters paid for these expenses through their individual research funding while the umbrella organisation used core funding to support the network. Organisations providing services to self-advocates contributed the time of their staff in supporting self-advocates to attend meetings and to conduct any preparatory/follow up work they undertook. Over 50 support staff had authored the four research reports analysed here, three of them had authored three reports, twelve two reports, and the rest of them one report, revealing an unstable base of supporters. Of those authoring three reports, two continued to actively support the network at the time of writing this paper. There was a shared understanding, however, that the sustainability of the network was dependent on supporters. As one self-advocate mentioned "We need more supporters for the [network] to keep going" (Inclusive Research Network, 2019).

Social support. One of the strengths of the network was that it was formed by existing smaller self-advocacy and research groups of about 4-8 people within service provider organisations (García Iriarte et al., 2014). Therefore, social relationships of self-advocates 
existed within local groups and developed between members across different groups over the years. Continued involvement of members and their supporters over time facilitated the development of a strong social network of self-advocates around research. Furthermore, some of the organisations providing services to self-advocates were regional branches of a bigger national service provider, which enabled self-advocates to meet at other events organised by their service provider. Monthly meetings also had a strong social component as personal updates were shared at the start, enabling people to know each other more closely, and group members interacted socially during lunch breaks. The following are examples of personal updates at a monthly meeting: "[member] has new cat", "[member] and [member] are going on holidays", "Welcome [supporter]. Congrats she had a baby girl”, “[member] has an App[lication] that can hear pilots talking to [anonymised city] airport" (Meeting minutes, May 2017)

Emotional support. Members of the network experienced several challenges conducting the research projects and great satisfaction and pride in their accomplishments. Several examples of how emotional support was provided to members exist within the documentation reviewed. For example, at one of the monthly meetings, the chairperson shared with the network a presentation she had given with other members at a national advocacy conference and the minutes recorded "everyone congratulated [members] on their presentation" (Meeting minutes, November 2016). The health of some of the members was fragile and they had to be hospitalised during the course of the projects. It was common that other members sent a card signed by everyone, as the following quote illustrates "[self-advocate] agreed to get cards that we could have to send to people who are sick or passed away (Meeting minutes, May 2017).

\section{Discussion}

This article has reviewed the work of an inclusive research group with the aim to explore decision-making processes about research production and the support used by the group to 
work together in research, which according to Walmsley, Strnadova, and Johnson (2018) may be the most important added value of inclusive research. To undertake the work reported here, self-advocates engaged in a critical review of their own work, which represents a novel approach in the inclusive research literature.

The inclusive research group recognised that their peer reviewed work was close to Bigby, Frawley, and Ramcharan (2014) description of collaborative inclusive research in which everyone's expertise contributed to the development of new methods and complex ideas were discussed before being presented in accessible ways. Reflecting on their own work, selfadvocates in this group clearly identified that they made the research decisions, as they were the only ones with a right to vote. The longitudinal review of the group's history brings to light that the group in fact had evolved from the early years in which training was university and professionally led, even if only self-advocates voted, to later times in which selfadvocates had developed strong leadership. We argue therefore that this way of doing and learning about research responds to a collaborative approach (Bigby, Frawley, and Ramcharan 2014). The analysis suggests that expertise from different members of the group contributed to the development of the research projects. Training continued to be critical to the group's learning and it encompassed learning about research skills, providing guidance about fieldwork, and working on specific aspects of research projects collaboratively. Ongoing material, social and emotional support underpinned the way the group learned about and engaged in research. The findings of this study suggest that research support including material, social and emotional support was a more encompassing category than training to describe how this group approached inclusive research. Self-advocates pointed out that all learned together and all needed support to conduct good research, with 'all' also referring to supporters, including university supporters. 
Nind et al. (2016) question whether training people with learning disabilities has become a pre-requisite to participate in inclusive research at the expense of losing their genuine expertise. The findings of this study indicate that on one hand, training was requested by selfadvocates to build on their skills and it was under their control. As Walmsley, Strnadova, and Johnson (2018) state, research training needs to be based on methodological aspects, expectations, and self-advocates' own priorities, as evidenced in this paper. On the other hand, self-advocates clearly differentiated between their role, as experts in learning disabilities (e.g. they valued their expertise in conducting fieldwork over the university supporters' expertise), and the role of university supporters, who guided them in methodological aspects of the research. The question about people with learning disabilities' acquiring skills resonates with that identified by the editors of the 2012 BJLD special issue. If complex ideas are explained, and therefore made accessible, then self-advocates can contribute to a conversation about those ideas. Is this understanding of new jargon and skills depriving people with learning disabilities from their original perspectives, or are they in fact in a better position to take part in research conversations about these ideas? In the case reviewed here, self-advocates chose research skills in order for them to become part of their repertoire and to complement their lived experiences.

Using Freire's (2003) pedagogical approach, language and research skills enabled selfadvocates' gradual realisation of inclusive research. They perceived the group as a research and as a self-advocacy platform, in which research was used to instigate policy change (Bane et al. 2012; García Iriarte et al. 2014), which according to Walmsley, Strnadova, and Johnson (2018) is a defining feature of inclusive research. All but one self-advocate in this group was 
paid for their research work and most of them only had the opportunity to immerse themselves in research once a month. Accordingly, 'self-advocates' was also preferred over 'co-researchers', as a more accurate reflection of their role. Strnadova and Walmsley (2018) in their critical review of the inclusive research literature point to the unresolved tensions between academic pressure for publication and self-advocacy needs. To tackle the absence of people with learning disabilities' voices in this discussion about critical inclusive research, the first three authors (university supporters) collaborated with self-advocates and their supporters on this article and on its easy-to-read version. Selfadvocates authoring this paper expressed satisfaction with the way in which we worked as a group and pointed that continued engagement between monthly meetings would increase their confidence as researchers. Their recommendations for new inclusive research groups included getting research training to complement their lived experiences, forming a steering group, making decisions through voting, and doing research on issues relevant to people with learning disabilities. They expressed that the added value of our work (see Walmsley, Strnadova, and Johnson 2018) is having people with learning disabilities in mind, and therefore publishing our work in easy-to-read language. The How We Work project was also an opportunity for the three university researchers authoring the paper to reflect on their role in the group. The importance of peer-reviewed publications for university supporters and easy-to-read reports for self-advocates had been openly discussed before by the group and this project aimed to address it with a peer-reviewed manuscript and a parallel easy-to-read version available on the group's website. The interest of self-advocates in overseeing the entire process of the manuscript publication, however, faded with time and university researchers undertook the revisions process. While participation in any activity of the group was always voluntary and self-advocates may have been satisfied with different levels of involvement, 
commitment to complete research work is an important conversation to have for the group moving forward.

We acknowledge that the type of collaboration we have analysed in this paper may be challenging if there is a lack of ongoing contact between university supporters and selfadvocates, however, we want to draw attention to the potential for further research exclusion of people with learning disabilities

(Goodley 2004) when they are not involved as co-authors and when research findings are not shared in accessible formats. We hope that being transparent about our way of working helps other self-advocates and researchers to assess how inclusive research can be a truly democratic endeavour, in which self-advocates can make decisions about the discussions they join and how.

\section{Limitations}

Substantial data was sourced to address the first aim of the study on how decisions were made, however, data on training and support provided to the group was not abundant. Further analysis of this particular aspect would merit researchers' attention, for example through supporters' reports. 


\section{References}

Bane, Geraldine, Doher, Martin, Flaherty, Josephine, Mahon, Ann, McDonagh, Padraic, Wolfe, Marie, Garcia Iriarte, Edurne, et al. (2012). "Relationships of people with learning disabilities in Ireland”. British Journal of Learning Disabilities 40(2): 109122. https://doi.org/10.1111/i.1468-3156.2012.00741.x

Bigby, Christy, Frawley, Patsie, \& Rachmaran, Paul (2014). “Conceptualizing Inclusive Research with People with Intellectual Disability". Journal of Applied Research in Intellectual Disabilities 27(1): 3-12. DOI: 10.1111/jar.12083

Blunt, Christopher, Blyth, Craig, Chapman, Rohhss, Frost, Louise, Hayward, Darren, Hughes, Richard, Perry, Barbara, \& Townson, Lou (2012). British Journal of Learning Disabilities, 40(2): 83-84. Doi:10.1111/j.1468-3156.2012.00748.x

British Journal of Learning Disabilities (2004). The place of people with "learning difficulties" in disability studies and research: introduction to this special issue, 32(2), 49-108.

British Journal of Learning Disabilities (2012). Special Issue: The research and work of learning disabled people with their allies and supporters, 40(2), 83-164.

Collins, Allan, Brown, John S., \& Newman, Susan E. (1989). “Cognitive apprenticeship: teaching the craft of reading, writing and mathematics". In Knowing, learning, and instruction: Essays in honor of Robert Glaser, edited by L.B Resnick. Hillsdale, NJ: Lawrence Erlbaum Associates.

European Commission (2019). Co-design towards the first strategic plan for Horizon Europe. A report on the web-based consultation and on the European Research and Innovation Days. 
Freire, Paulo. (2003). Pedagogy of the oppressed. New York: Continuum.

García Iriarte, Edurne, O’Brien, Patricia, \& Chadwick, Darren (2014). Involving people with intellectual disabilities within research teams: Lessons learned from an Irish experience. Journal of Policy and Practice in Intellectual Disabilities, 11(2), 149157.

García Iriarte, Edurne, O’Brien, Patricia, McConkey, Roy, Wolfe, Marie, \& O’Doherty, Siobhain (2014). "Identifying the key concerns of Irish persons with intellectual disability". Journal of Applied Research in Intellectual Disabilities, 27(6): 564-75. DOI: $10.1111 /$ jar.12099.

Goodley, Daniel (2004). “The place of people with 'learning difficulties' in disability studies and research: introduction to this special issue". British Journal of Learning Disabilities, 32(2): 49-51. https://doi.org/10.1111/j.1468-3156.2004.00279.x

Inclusive Research Network (2009). Where we live. A national study done by members of the Inclusive Research Network through surveys. Galway: National Federation of Voluntary Bodies; Dublin: National Institute for Intellectual Disability. Available from http://www.fedvol.ie/Inclusive_Research_Network_IRN/Default.241.html.

Inclusive Research Network (2010). Relationships and Supports study: People with intellectual disability in Ireland. Dublin: National Institute for Intellectual Disability Ireland; Galway: National Federation of Voluntary Bodies. Available from http://www.fedvol.ie/Inclusive_Research_Network_IRN/Default.241.html

Inclusive Research Network (2015). Our homes. Home and independence project. Dublin: School of Social Work and Social Policy, Trinity College Dublin; Limerick: Department of Clinical Therapies, University of Limerick; Galway: National Federation of Voluntary Bodies. Available from http://www.fedvol.ie/Inclusive_Research_Network_IRN/Default.241.html 
Inclusive Research Network (2019). Doctors and us. What is like for people with learning disabilities to go to the doctor in Ireland. Limerick: School of Allied Health, University of Limerick; Dublin: School of Social Work and Social Policy, Trinity College Dublin; Galway: National Federation of Voluntary Service Providers; Certificate in Contemporary Living/School of Applied Social Studies, University College Cork. Available from http://www.fedvol.ie/Inclusive_Research_Network_IRN/Default.241.html Journal of Applied Research in Intellectual Disabilities (2014). "Special Issue: New Directions in Inclusive Research" 27(1): 1-84.

Kramer, Jessica M., Kramer, John, Garcia Iriarte, Edurne, Hammel, Joy (2011). "Following through to the end: The use of inclusive strategies to analyse and interpret data in participatory action research with individuals with intellectual disabilities". Journal of Applied Research in Intellectual Disabilities, 24(3): 263-273. DOI:

10.1111/j.1468-3148.2010.00602.x.

Hecker, Susanne, Bonney, Rick, Haklay, Muki, Hölker, Heribert, Goebel, Claudia, Gold, Margaret, et al. (2018). "Innovation in Citizen Science - Perspectives on SciencePolicy Advances”. Citizen Science: Theory and Practice, 3(1): 4,. 1-14, DOI: https://doi.org/10.5334/cstp.114

Nind, Melaine (2016). "Towards a second generation of inclusive research". In Inklusive Forschung, edited by Tobias Buchner, Oliver Koenig and Saskia Schuppener. Bad Heilbrunn: Klinkhardt.

Nind, Melanie, Chapman, Rohhss, Seale, Jane, \& Tilley, Liz. (2015). “The conundrum of training and capacity building for people with learning disabilities doing research". Journal of Applied Research in Intellectual Disabilities, 29(6): 542-551. DOI: $10.1111 /$ jar.12213 
Pallisera Díaz, Maria, Puyaltó Rovira, Carol, Fullana Noell, Judit, Vila Suñé, Montserrat, \& Martin Pazos, Raquel (2015). “An inclusive Research experience. People with intellectual disabilities as advisors in a research about transition to adult life". Revista Iberoamericana de Educación, 69(2): 147-166.

Patton, Michael Q. (2015). Qualitative Research and Evaluation Methods, $4^{\text {th }}$ Edition. California: Sage.

Salmon, Nancy, Garcia Iriarte, Edurne, Donohoe, Brian, Murray, Laura, Singleton, Greg, Barrett, Mary, \& Dillon, Marie. (2019). “Our Homes: An inclusive study about what moving house is like for people with intellectual disabilities in Ireland". British Journal of Learning Disabilities, 47(1): 19-28. https://doi.org/10.1111/bld.12251

Strnadova, I. \& Cumming, M. (2014). People with Intellectual Disabilities Conducting Research: New Directions for Inclusive Research. Journal of Applied Research in Intellectual Disabilities, 27(1), 1-2.

Strnadova, Iva \& Walmsley, Jan (2017). "Peer-reviewed articles on inclusive research: Do co-researchers with intellectual disabilities have a voice?" Journal of Applied Research in Intellectual Disabilities 31(1): 132-141. DOI: 10.1111/jar.12378

Tierney, Edel, Curtis, Stephen, \& O’Brien, Patricia (2009). The Inclusive Research Network: A participatory action research project. A joint initiative of the National Federation of Voluntary Bodies and the National Institute for Intellectual Disability. Available from http://www.fedvol.ie/Reports_by the_Inclusive_Research_Network/Default.2084.h $\underline{\mathrm{tml}}$. 
Tuffrey-Wijne Irene \& Butler Gary (200 9). “Co-researching with people with learning disabilities: an experience of involvement in qualitative data analysis". Health Expectations, 13(2): 174-184. DOI: 10.1111/j.1369-7625.2009.00576.x.

United Nations (2006). Convention on the Rights of Persons with Disabilities. Accessed 10 June 2019 from https://www.un.org/development/desa/disabilities/convention-onthe-rights-of-persons-with-disabilities.html.

Walmsley Jan \& Johnson, Kelly. (2003). Inclusive Research with People with Learning Disabilities: Past, Present and Futures. London: Jessica Kingsley Publishers.

Walmsley, Jan, Strnadova, Iva, \& Johnson, Kelly. (2018). "The added value of inclusive research" Journal of Applied Research in Intellectual Disabilities, 31(5): 751-759. DOI: $10.1111 /$ jar.12431. 